\title{
Proclination-induced changes in the labial cortical bone thickness of lower incisors
}

\author{
Filipova $\mathrm{D}^{1}$, Dostalova $\mathrm{T}^{1}$, Filipi $\mathrm{V}^{2}$, Kaminek $\mathrm{M}^{3}$ \\ Motol University Hospital, Department of Stomatology, Charles University, Second Medical Faculty, Prague, \\ Czech Republic. diana.gabcova@gmail.com
}

\section{ABSTRACT}

OBJECTIVES: We sought to objectivize the overall alveolar bone thickness changes in lower incisors after orthodontic intervention.

BACKGROUND: The effect of orthodontic treatment on the cortical bone, specifically the clinical implications of proclination-induced change, have long been a matter of dispute.

METHODS: Cone-beam computed tomographs of 58 patients were obtained before and after treatment and labial cortical bone thickness and overall alveolus width were measured in sagittal sections in the distance of 3, 6, 9 and $12 \mathrm{~mm}$ apically from the cemento-enamel junction.

RESULTS: A statistically significant decrease of the cortical bone thickness in all four incisors was found at the levels 3,6 and $9 \mathrm{~mm}(p<0.05)$, with mean differences of $0.19,0.10$ and $0.14 \mathrm{~mm}$, respectively. The cortical bone thickness at the level of $12 \mathrm{~mm}$ and alveolar width at all the levels showed no significant changes $(p>$ 0.05). Moreover, no correlation was found between bone thickness change and extent of the incisor movement. CONCLUSION: Our results point to a marked cortical bone loss after proclination of lower incisors, furnishing a sound basis for caution in treatment planning due to the considerable risk of alveolar defect development, especially in patients with low initial bone thickness (Tab. 6, Fig. 2, Ref. 25). Text in PDF www.elis.sk.

KEY WORDS: orthodontics, cone-beam computed tomography, incisor, cortical bone, bone remodeling.

\begin{abstract}
Abbreviations: $\mathrm{CBCT}$ - cone-bean computed tomography, SD standard deviation, T1 - before treatment, T2 - after treatment, IMPA - Incisor mandibular plane angle, L1-APo - position of the lower incisor relative to A-Pogonion line, CEJ - Cementumenamel junction
\end{abstract}

\section{Introduction}

The position of the lower incisors is of paramount importance in the orthodontic diagnosis and treatment. To understand the failures and potential perils associated with the interference in this area, it is necessary to consider the precise mechanical and biological mechanisms that underlie their artificial movement. In turn, this requires understanding of the processes in terms of their multifactorial limitations imposed by the periodontal status

${ }^{1}$ Charles University, Second Faculty of Medicine, Motol University Hospital, Department of Stomatology, Prague, Czech Republic, ${ }^{2}$ Sorriso Dental, Brno, Czech Republic, and ${ }^{3}$ Palacký University, Faculty of Medicine and Dentistry, Institute of Dentistry and Oral Sciences, Olomouc, Czech Republic

Address for correspondence: D. Filipova, Motol University Hospital, Department of Stomatology, Charles University, Second Medical Faculty, V Uvalu 84, CZ-150 06 Prague, Czech Republic. Phone: +420774888473

Acknowledgement: This research was supported by The Internal Grant Agency of the Czech Ministry of Health (IGA MZCR 13351-4) and Motol University Hospital (00064203 FN Motol). in the area (1), the morphology of the symphysis $(2,3)$ as well as the dimensions of the anterior alveolus (2). These factors must be considered in the treatment plan, balancing the speed and the extent of movement to achieve a stable final position on one side and the notable risk of iatrogenic damage on the other $(2,4)$.

As yet, several studies have analyzed periodontal status after the treatment, reporting the risk of gingival retraction, external root resorption, dehiscences and fenestrations $(1,4-7)$. In their influential paper on this topic, MULIE AND HOEVE (4) were the first to draw the attention of the clinical community to the inhibition of the orthodontic movement, dehiscences and fenestrations associated with the contact of the root and the cortical plate. Nonetheless, alveolar defects are consistently observed in treatment-naive individuals (8-11). Ergo, this initially reduced bone support, especially in the case of a narrow and high symphysis (12), markedly increases the potential risk of progressive bone loss if combined with heavy forces and short-term orthodontic activation not allowing complete adaptation of the bone (13). At the same time, the majority of authors agrees on the incidence of these alveolar defects being at a clinically acceptable level and do not consider orthodontic intervention contraindicated even in patients with potential risks $(2,14)$.

In this study, we addressed the question stated above by means of cone-bean computed tomography (CBCT), which proved to be an accurate imaging tool in investigations of this nature (10), and evaluated the labial cortical bone thickness and the overall alveolar bone thickness in lower incisors before and after orthodontic 
155-160

treatment. Our premise was that their proclination should induce a drop in the cortical bone thickness at the levels more distant from the tooth apex and, at the same time, leave the deep areas around the apex itself unchanged.

\section{Material and methods}

A total of 58 patients ( 39 women, average age 23.2 years, SD $6.5)$ from a private orthodontic practice were enrolled in this retrospective cross-sectional study. Complete treatment records of all the subjects, including pretreatment and posttreatment measurements and CBCT scans, were collected. Only patients with Angle class I or class II malocclusion, with mild to moderate crowding were selected. All patients had complete dental arches (besides third molars) without active eruption of teeth. The following exclusion criteria were implemented: any medical concerns of nonorthodontic nature, class III malocclusion, periodontal diseases (gingival inflammation and bone resorptions), severe crowding in the lower dental arch, missing teeth, history of previous orthodontic treatment and trauma, prosthetic restoration, endodontic, periodontal pathologies and surgeries in the evaluated region. All the subjects completed orthodontic treatment lead by one orthodontist with fixed appliance, without extractions, where crowding was alleviated by the proclination of the lower incisors. Straightwire mechanics and brackets with Roth prescription, with the .022 " slot, were used. All patients signed informed consent with the retrospective analysis of their anonymized data and the study was approved by the Ethical Committee of Charles University, 2nd Faculty of Medicine and the Motol University Hospital (IRB approval No. EK-973IGA 1.12/11).

\section{Cephalometric analysis}

Cephalometric analysis was performed at both time points using Dolphin Imaging Software (Dolphin Imaging, Chatsworth, CA, US). Quantitative assessment (angular and linear measurements) of the incisor movement was performed. The axial inclination of lower incisors was measured as the incisor mandibular plane angle (IMPA) in degrees. Mandibular incisor protrusion in millimeters was measured as the position of the lower incisor relative to APogonion line (L1-APo).

\section{CBCT analysis}

CBCT scans were acquired for each patient prior to the treatment (T1) and after treatment (T2) using the SkyView CBCT scanner (MyRay, Imola, Italy) at the following settings: $90 \mathrm{kVp}, 10 \mathrm{~mA}$, exposure time 6.88 seconds, $360^{\circ}$ revolution and $0.23 \mathrm{~mm}$ voxel size. All scans were processed according to the protocol presented by $\mathrm{CHO}(15)$, where the $3 \mathrm{D}$ image is reoriented according to two reference planes, naso-frontozygomatic plane and Frankfort horizontal plane, to minimize errors from nonstandard head position.

Each CBCT scan was analyzed using DentalPlan (MyRay, Imola, Italy) software. Sagittal sections were generated automatically along the long axis (center of the root canal) of each lower incisor (Fig. 1A). Cementum-enamel junctions (CEJs) of the incisors were identified on the sagittal sections and the measurement levels were set at the distance of 3, 6, 9 and $12 \mathrm{~mm}$ in the apical direction from the CEJ. Finally, cross sectional images of individual incisors perpendicular to their long axis were obtained for each measurement level (Fig. 1B).

Labial cortical bone thickness was measured on these axial sections in the plane of the widest labiolingual root dimension (Fig. 2). This protocol provided eight measurements of the cortical bone thickness for each incisor, four at $\mathrm{T} 1$ and four at $\mathrm{T} 2$. The overall width of the alveolus in the same site was also measured. All measurements were taken by the same person.

\section{Statistical analysis}

All statistical analyses were performed using the Statistica 12 software (StatSoft Inc., Tulsa, Oklahoma, USA). Variables were checked for normal distribution by graphing the normal probability

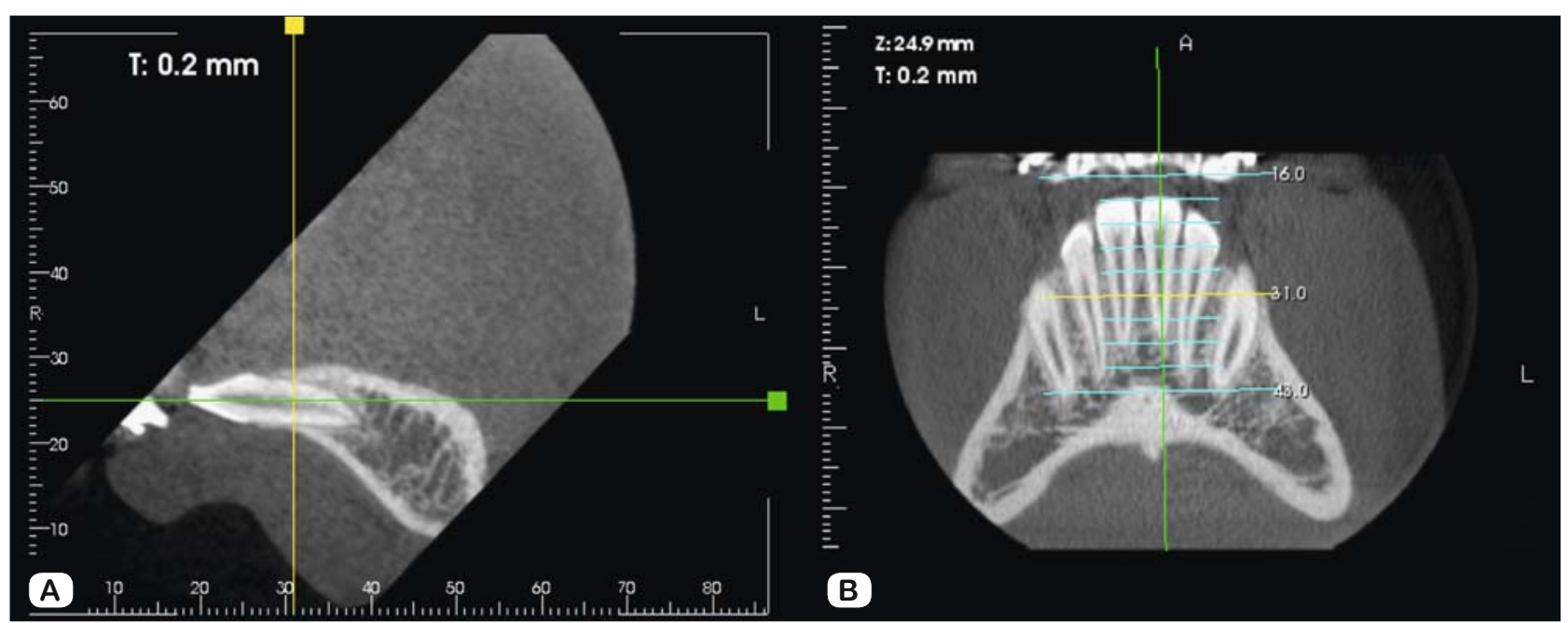

Fig. 1. Reconstruction of the sections in the long axis of the incisor. A. Sagittal section. B. Frontal view. Construction of the sections perpendicular to the long axis. 
Tab. 1. Measurements obtained by cephalometric analysis before (T1) and after (T2) the treatment.

\begin{tabular}{|c|c|c|c|c|c|c|c|c|}
\hline \multirow{2}{*}{ Variable } & \multicolumn{3}{|c|}{ T1 } & \multicolumn{3}{|c|}{$\mathrm{T} 2$} & \multirow{2}{*}{$\begin{array}{l}\text { Mean difference } \\
\mathrm{T} 2-\mathrm{T} 1(\Delta)[\mathrm{mm}]\end{array}$} & \multirow{2}{*}{$\begin{array}{c}\text { T-test } \\
\mathrm{p}\end{array}$} \\
\hline & Mean $[\mathrm{mm}]$ & $\mathrm{SD}[\mathrm{mm}]$ & Range [mm] & Mean $[\mathrm{mm}]$ & $\mathrm{SD}[\mathrm{mm}]$ & Range [mm] & & \\
\hline$\overline{\mathrm{IMPA}}\left(^{\circ}\right)$ & 92.60 & 7.04 & $79.6-107.6$ & 98.40 & 7.13 & $85.8-113.0$ & 5.80 & $0.000 *$ \\
\hline L1-APo (mm) & 1.62 & 2.32 & $-2.3-4.9$ & 3.85 & 2.00 & $0.2-8.3$ & 2.23 & $0.000 *$ \\
\hline
\end{tabular}

IMPA, incisor mandibular plane angle, L1-APo, position of the lower incisor relative to A-Pogonion line, ${ }^{*} \mathrm{p}<0.05$ (significant difference)

Tab. 2. Labial cortical bone thickness in each incisor before (T1) and after (T2) the treatment.

\begin{tabular}{|c|c|c|c|c|c|c|c|}
\hline \multirow{2}{*}{$\begin{array}{l}\text { Mandibular } \\
\text { incisor }\end{array}$} & \multirow[b]{2}{*}{$\begin{array}{c}\text { Measurement } \\
\text { level }[\mathrm{mm}]\end{array}$} & \multicolumn{2}{|l|}{ T1 } & \multicolumn{2}{|l|}{$\mathrm{T} 2$} & \multirow[b]{2}{*}{$\begin{array}{l}\text { Mean difference } \\
\mathrm{T} 2-\mathrm{T} 1(\Delta)[\mathrm{mm}]\end{array}$} & \multirow[b]{2}{*}{$\begin{array}{c}\text { T-test } \\
\mathrm{p}\end{array}$} \\
\hline & & $\begin{array}{l}\text { Bone thickness (SD) } \\
{[\mathrm{mm}]}\end{array}$ & $\begin{array}{l}\text { Range } \\
{[\mathrm{mm}]}\end{array}$ & $\begin{array}{l}\text { Bone thickness (SD) } \\
{[\mathrm{mm}]}\end{array}$ & $\begin{array}{l}\text { Range } \\
{[\mathrm{mm}]}\end{array}$ & & \\
\hline \multirow{4}{*}{$\begin{array}{l}\text { Right lateral } \\
(42)\end{array}$} & 3 & $0.35(0.22)$ & $0.0-0.8$ & $0.19(0.13)$ & $0.0-0.5$ & 0.16 & $0.000 *$ \\
\hline & 6 & $0.45(0.16)$ & $0.0-0.8$ & $0.29(0.20)$ & $0.0-0.6$ & 0.16 & $0.000^{*}$ \\
\hline & 9 & $0.97(0.37)$ & $0.2-2.0$ & $0.66(0.41)$ & $0.2-1.6$ & 0.31 & $0.000 *$ \\
\hline & 12 & $1.33(0.40)$ & $0.5-1.9$ & $1.25(0.57)$ & $0.4-2.8$ & 0.08 & 0.129 \\
\hline \multirow{4}{*}{$\begin{array}{l}\text { Right central } \\
\text { (41) }\end{array}$} & 3 & $0.35(0.24)$ & $0.0-0.8$ & $0.24(0.18)$ & $0.0-0.5$ & 0.11 & $0.001^{*}$ \\
\hline & 6 & $0.40(0.25)$ & $0.0-1.1$ & $0.29(0.17)$ & $0.0-0.8$ & 0.11 & $0.020 *$ \\
\hline & 9 & $0.90(0.48)$ & $0.2-2.2$ & $0.76(0.44)$ & $0.0-1.6$ & 0.14 & $0.003 *$ \\
\hline & 12 & $1.23(0.41)$ & $0.5-2.4$ & $1.17(0.38)$ & $0.5-2.0$ & 0.06 & 0.015 \\
\hline \multirow{4}{*}{$\begin{array}{l}\text { Left central } \\
(31)\end{array}$} & 3 & $0.30(0.23)$ & $0.0-0.8$ & $0.15(0.15)$ & $0.0-0.5$ & 0.15 & $0.000^{*}$ \\
\hline & 6 & $0.38(0.23)$ & $0.0-1.0$ & $0.31(0.46)$ & $0.0-1.0$ & 0.07 & 0.088 \\
\hline & 9 & $0.86(0.46)$ & $0.2-1.6$ & $0.70(0.45)$ & $0.2-2.0$ & 0.16 & $0.004 *$ \\
\hline & 12 & $1.22(0.39)$ & $0.5-2.1$ & $1.15(0.48)$ & $0.2-2.5$ & 0.07 & 0.123 \\
\hline \multirow{3}{*}{$\begin{array}{l}\text { Left lateral } \\
\text { (32) }\end{array}$} & 3 & $0.38(0.36)$ & $0.0-1.1$ & $0.06(0.13)$ & $0.0-0.5$ & 0.32 & $0.000^{*}$ \\
\hline & 9 & $0.71(0.33)$ & $0.2-1.6$ & $0.64(0.39)$ & $0.0-1.5$ & 0.08 & $0.048 *$ \\
\hline & 12 & $1.36(0.39)$ & $0.7-2.5$ & $1.32(0.38)$ & $0.7-2.4$ & 0.04 & 0.147 \\
\hline
\end{tabular}

$* \mathrm{p}<0.05$ (significant difference)

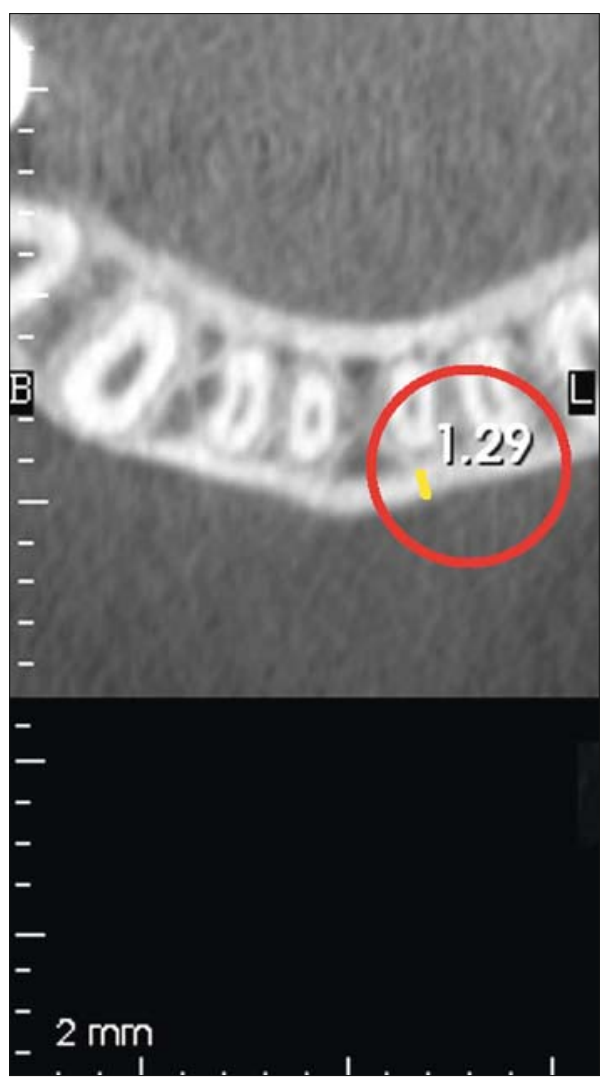

Fig. 2. Cortical bone thickness measurement at one level. Cortical thickness marked with the yellow line. plot and using Kolmogorov-Smirnov test, revealing global insignificant departures from normality.

Descriptive statistics that included the average, standard deviation, and minimum and maximum values are provided for all the measured variables. The changes in the cephalometric measurements and in the cortical bone thickness after the treatment were evaluated using paired t-tests. Correlation analyses with Pearson correlation coefficient were used to determine the measure of association between the extent of the incisor movement and the extent of the bone loss.

The significance value of $p<0.05$ was adopted for all the comparisons.

\section{Results}

No statistically significant differences were found between male and female subjects $(p>0.05)$, therefore the measurements obtained from male and female subjects were pooled in the final evaluation. The random method error ranged from 0.13 to 0.87 for all variables.

\section{Cephalometric analysis}

The results of T1 and T2 cephalometric measurements are listed in Table 1. There was a significant increase in IMPA where the mean difference after the treatment was $5.8^{\circ}(\mathrm{p}<0.001)$. L1-APo) increased significantly by $2.23 \mathrm{~mm}$ after treatment $(\mathrm{p}<0.001)$. 
Tab. 3. Labial cortical bone thickness in all four incisors before (T1) and after (T2) the treatment.

\begin{tabular}{|c|c|c|c|c|c|c|}
\hline \multirow{2}{*}{$\begin{array}{l}\text { Measurement level } \\
{[\mathrm{mm}]}\end{array}$} & \multicolumn{2}{|c|}{$\mathrm{T} 1$} & \multicolumn{2}{|c|}{$\mathrm{T} 2$} & \multirow[b]{2}{*}{$\begin{array}{l}\text { Mean difference } \\
\text { T2-T1 }(\Delta)[\mathrm{mm}]\end{array}$} & \multirow[b]{2}{*}{$\begin{array}{c}\text { T-test } \\
\mathrm{p}\end{array}$} \\
\hline & $\begin{array}{l}\text { Bone thickness } \\
\text { (SD) }[\mathrm{mm}]\end{array}$ & $\begin{array}{l}\text { Range } \\
{[\mathrm{mm}]}\end{array}$ & $\begin{array}{l}\text { Bone thickness } \\
\text { (SD) }[\mathrm{mm}]\end{array}$ & $\begin{array}{l}\text { Range } \\
{[\mathrm{mm}]}\end{array}$ & & \\
\hline 3 & $0.35(0.27)$ & $0-1.1$ & $0.16(0.16)$ & $0-0.5$ & 0.19 & $0.000^{*}$ \\
\hline 6 & $0.41(0.23)$ & $0-1.3$ & $0.31(0.21)$ & $0-1.0$ & 0.10 & 0.000 * \\
\hline 9 & $0.83(0.41)$ & $0.2-2.2$ & $0.69(0.43)$ & $0-2.0$ & 0.14 & $0.000^{*}$ \\
\hline 12 & $1.27(0.40)$ & $0.5-2.5$ & $1.22(0.45)$ & $0.2-2.8$ & 0.05 & 0.090 * \\
\hline
\end{tabular}

Tab. 4. Alveolus width in each incisor before (T1) and after (T2) the treatment.

\begin{tabular}{|c|c|c|c|c|c|c|c|}
\hline \multirow[b]{2}{*}{$\begin{array}{l}\text { Mandibular } \\
\text { incisor }\end{array}$} & \multirow[b]{2}{*}{$\begin{array}{c}\text { Measurement } \\
\text { level }[\mathrm{mm}]\end{array}$} & \multicolumn{2}{|l|}{$\mathrm{T} 1$} & \multicolumn{2}{|l|}{$\mathrm{T} 2$} & \multirow[b]{2}{*}{$\begin{array}{l}\text { Mean difference } \\
\mathrm{T} 2-\mathrm{T} 1(\Delta)[\mathrm{mm}]\end{array}$} & \multirow[b]{2}{*}{$\begin{array}{c}\text { T-test } \\
\mathrm{p}\end{array}$} \\
\hline & & $\begin{array}{c}\text { Bone thickness (SD) } \\
{[\mathrm{mm}]}\end{array}$ & $\begin{array}{l}\text { Range } \\
{[\mathrm{mm}]}\end{array}$ & $\begin{array}{c}\text { Bone thickness (SD) } \\
{[\mathrm{mm}]}\end{array}$ & $\begin{array}{l}\text { Range } \\
{[\mathrm{mm}]}\end{array}$ & & \\
\hline \multirow{4}{*}{$\begin{array}{l}\text { Right lateral } \\
(42)\end{array}$} & 3 & $7.11(0.71)$ & $5.7-8.8$ & $7.13(0.77)$ & $5.9-8.5$ & -0.02 & 0.870 \\
\hline & 6 & $7.05(0.74)$ & $5.4-8.6$ & $6.98(0.81)$ & $5.4-9.0$ & 0.07 & 0.507 \\
\hline & 9 & $7.08(1.44)$ & $4.8-10.4$ & $6.93(1.50)$ & $4.5-10.2$ & 0.15 & 0.196 \\
\hline & 12 & $7.22(1.82)$ & $4.1-11.1$ & $7.17(2.08)$ & $3.6-11.9$ & 0.05 & 0.710 \\
\hline \multirow{4}{*}{$\begin{array}{l}\text { Right central } \\
\text { (41) }\end{array}$} & 3 & $6.68(0.95)$ & $4.7-9.2$ & $6.56(0.84)$ & $5.0-8.5$ & 0.12 & 0.244 \\
\hline & 6 & $6.71(0.96)$ & $4.4-8.8$ & $6.71(0.88)$ & $5.1-8.5$ & 0.00 & 0.975 \\
\hline & 9 & $6.70(1.4)$ & $4.7-10.6$ & $6.65(1.29)$ & $4.7-9.7$ & 0.05 & 0.603 \\
\hline & 12 & $7.45(1.80)$ & $4.3-11.4$ & $7.19(1.76)$ & $4.5-11.3$ & 0.27 & $0.018^{*}$ \\
\hline \multirow{4}{*}{$\begin{array}{l}\text { Left central } \\
(31)\end{array}$} & 3 & $6.70(0.73)$ & $5.2-7.8$ & $6.60(0.95)$ & $4.8-8.4$ & 0.10 & 0.368 \\
\hline & 6 & $6.48(0.95)$ & $4.7-8.7$ & $6.36(0.81)$ & $4.8-8.2$ & 0.12 & 0.277 \\
\hline & 9 & $6.78(1.64)$ & $4.8-10.9$ & $6.54(1.66)$ & $4.1-9.7$ & 0.24 & $0.012 *$ \\
\hline & 12 & $7.28(1.99)$ & $4.5-12.0$ & $7.13(1.98)$ & $4.4-11.1$ & 0.15 & 0.084 \\
\hline \multirow{3}{*}{$\begin{array}{l}\text { Left lateral } \\
\text { (32) }\end{array}$} & 3 & $6.97(0.64)$ & $5.4-8.2$ & $6.88(1.02)$ & $4.9-8.9$ & 0.09 & 0.420 \\
\hline & 9 & $6.85(1.38)$ & $4.2-10.3$ & $6.80(1.44)$ & $4.5-10.4$ & 0.03 & 0.822 \\
\hline & 12 & $7.44(1.70)$ & $4.9-11.3$ & $7.29(1.82)$ & $4.1-11.4$ & 0.15 & 0.093 \\
\hline
\end{tabular}

$*_{\mathrm{p}}<0.05$ (significant difference)

Tab. 5. Labial cortical bone thickness in all four incisors before (T1) and after (T2) the treatment.

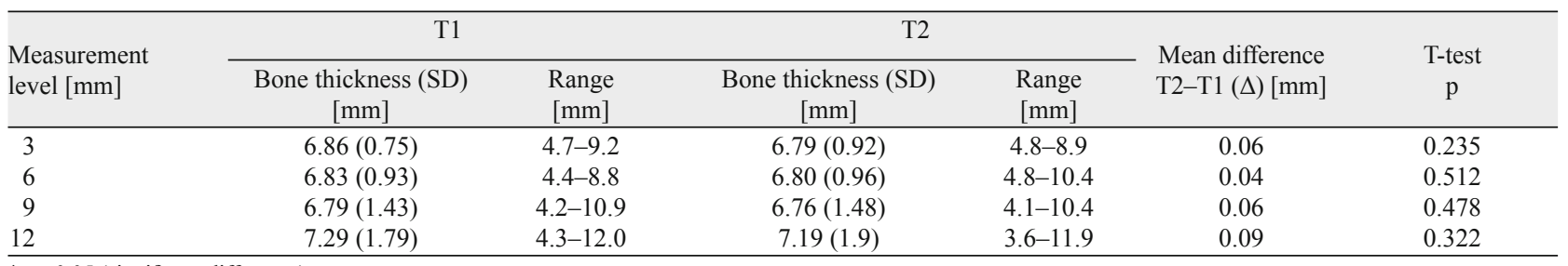

$*_{\mathrm{p}}<0.05$ (significant difference)

\section{CBCT analysis}

The measurements of the cortical bone thickness for each incisor before and after orthodontic treatment are detailed in Table 2.

The bone thickness significantly decreased after the treatment at the 3-mm level for all four incisors: the mean difference was $0.16,0.11,0.15$ and $0.32 \mathrm{~mm}$ in the teeth $42,41,31$ and 32 , respectively ( $\mathrm{p}<0.01$ for all the measurements). The bone thickness also decreased significantly at the $6-\mathrm{mm}$ level in the teeth 42,41 and $32(0.16,0.11$ and $0.15 \mathrm{~mm}$, respectively) $(\mathrm{p}<0.001$, $\mathrm{p}=0.020, \mathrm{p}<0.001$, respectively). Bone decrease at the $6-\mathrm{mm}$ measurement level in the left central incisor $(0.07 \mathrm{~mm})$ was not significant $(p=0.088)$. A significant decrease of the bone thickness at the $9-\mathrm{mm}$ measurement level was found in all four incisors with mean differences of $0.31,0.14,0,16$ and $0.08 \mathrm{~mm}$ in the teeth 42 , 41,31 and 32 , respectively $(\mathrm{p}<0.001, \mathrm{p}=0.003,0.004$ and 0.048 , respectively). At the most apical level, $12 \mathrm{~mm}$ from the CEJ, the posttreatment decrease was significant only in right central incisor with the mean difference of $0.06 \mathrm{~mm}(\mathrm{p}=0.015)$. Changes found in the teeth 42,31 and 32 did not reach significance $(\mathrm{p}>0.05)$, with mean differences smaller than $0.1 \mathrm{~mm}$.

The overall results for all four incisors together are shown in the Table 3. Statistically significant decrease of the cortical bone thickness was found in measurement levels 3,6 and $9 \mathrm{~mm}(\mathrm{p}<$ 0.001 ), with mean differences $0.19,0.10$ and $0.14 \mathrm{~mm}$, respectively. Posttreatment change was not significant at $12 \mathrm{~mm}$ measurement level $(\mathrm{p}=0.090)$, where the mean difference was as small as $0.05 \mathrm{~mm}$.

The measurements of the width of the alveolus for each incisor before and after orthodontic treatment are presented in Table 4. The acquired values showed wide inter-individual variability. 
Tab. 6. The analysis of correlation of the bone thickness change and the extent of the incisor movement.

\begin{tabular}{lccc}
\hline Measurement & IMPA & & L1-APo \\
\cline { 2 - 3 } level $[\mathrm{mm}]$ & $\mathrm{R}$ & $\mathrm{R}$ \\
\hline 3 & -0.088 & 0.087 \\
6 & 0.169 & -0.242 \\
9 & 0.062 & -0.212 \\
12 & 0.107 & 0.023 \\
\hline
\end{tabular}

IMPA - incisor mandibular plane angle, L1-Apo - position of the lower incisor relative to A-Pogonion line,

$\mathrm{R}$ - Pearson correlation coefficient

The alveolar width changes were insignificant $(p>0.05)$ in all teeth at all the measurement levels with the exception of the $9-\mathrm{mm}$ level in the tooth $31(\mathrm{p}=0.012)$ and the $12-\mathrm{mm}$ level in the tooth $41(\mathrm{p}=0.018)$.

The overall results of alveolar width in all four incisors are shown in Table 5. Posttreatment change was not significant at any measurement level ( $p>0.05)$, showing only an ambiguous trend for post-treatment alveolar width decrease.

Correlation analysis (Tab. 6) implies that there is no linear correlation between the cortical bone thickness change and IMPA changes. On the other hand, a weak negative correlation was found between bone thickness change and L1-APo change at the 6-mm and $9-\mathrm{mm}$ measurement levels $(\mathrm{R}=-0.242$ and -0.212 , respectively). There were no correlations at the $3-\mathrm{mm}$ and $12-\mathrm{mm}$ measurement levels $(\mathrm{R}=0.087$ and 0.023$)$.

\section{Discussion}

The imaging approach presented here provides a biologically plausible model of cortical alveolar bone remodeling and a basis for testable clinical predictions which, we hope, will aid in further pathophysiological and therapeutic research in this area. Our findings of a significant labial cortical bone loss after the proclination of the lower incisors are very much in keeping with some previous clinical reports $(1,4,5,7,12-14,16)$, underscoring the possible negative effects of this type of orthodontic treatment.

The remodeling of alveolar bone around the moving tooth during the treatment is one of the hallmarks of the physiology of orthodontics, with cortical bone creating a seemingly difficultto-breach anatomical border to this movement (2). However, the decreasing initial thickness of the bone associated with degrading density (17) makes the thin layer of the cortical bone in incisor area particularly prone to microfractures during the orthodontic movement, resulting in bone loss (18). The selective inclusion of patients with crowding in this study and hence a specific type of movement may well explain the absence of significant changes of cortical bone thickness at the 12-mm measurement level, as the tooth apex did not change its position to such an extent to markedly affect the thickness of the surrounding bone. Moreover, and completely corresponding to our prior hypothesis, the thickness of the cortical bone at the measurement levels of 3, 6 and $9 \mathrm{~mm}$ was reduced in most cases.

Nonetheless, we may provide only conjectures on the extent the cortical bone loss is related to the bone volume before the treatment, as no formal correlation was found between the extent of the orthodontic movement and the bone loss in our analyses, possibly due to limited number of patients. Its average increase of $5.8^{\circ}$ according to the cephalometric analysis was combined with an increase of L1-Apo distance by $2.33 \mathrm{~mm}$ on average, but both failed to show significant correlation with the bone loss extent.

Turning to the alveolar width change, our findings of minimal differences between the pretreatment and posttreatment value, under the resolution level of the device, also did not reach significance, which may be interpreted as a consequence of bone apposition on the lingual side during the proclination of the incisors. This result corresponds to the basic orthodontic axiom of bone remodeling around the tooth in the same extent during tooth movement (2).

Due to expected bone regeneration capacity, it would be expedient to continue with subsequent measurements in these patients in the retention phase. However, CBCT is usually not indicated at this stage.

An important point needs to be considered with regards to our results - the spatial resolution of the used imaging method. Several prior studies analyzed bone support of the incisors using various types of radiographs $(1,2,4-7)$, but burdened with a major interference of the structure superimposition in the analysis of two-dimensional scans, bone loss tends to be underestimated in radiographs $(19,20)$. Computer tomography is able to provide precise information on the labio-lingual bone support $(21,23)$, resolving the above-described distortion and superimposition of the structures, with acceptable accuracy for this purpose in case of minimal bone thickness over $0.5 \mathrm{~mm}$ (24). This threshold, corresponding to $2-3$ voxels in the scans, is very low, even when considering the tendency of CBCT to overestimate alveolar defects (25). From the clinical perspective, bone of this thickness can be considered a defect, hence not disproving the findings of our study. Nevertheless, higher resolution, though technically possible, is clearly precluded in the clinical practice due to medical and ethical concerns associated with increased radiation dose.

This approach represents a refinement and synthesis of ideas hypothesized in previous studies, pointing to marked proclinationinduced disruption of cortical bone thickness in the areas close to the CEJ. Even though no correlation was found between the extent of orthodontic movement and the bone loss in our analyses, the possible lack of statistical power in this size of patient population does not allow us to proceed without due caution, mainly in patients with low initial bone thickness. Further prospective studies in well-defined patient populations will be necessary to elucidate this issue in its complexity.

\section{References}

1. Yared KF, Zenobio EG, Pacheco W. Periodontal status of mandibular central incisors after orthodontic proclination in adults. Am J Orthod Dentofacial Orthop 2006; 130: 6.e1-8.

2. Handelman CS. The anterior alveolus: Its importance in limiting orthodontic treatment and its influence on the occurrence of iatrogenic sequelae. Angle Orthod 1996; 66: 95-110. 
155-160

3. Gracco A, Luca L, Bongiorno MC, Siciliani G. Computed tomography evaluation of mandibular incisor bony support in untreated patients. Am J Orthod Dentofacial Orthop 2010; 138: 179-187.

4. Mulie RM, Hoeve AT. The limitations of tooth movement within the symphysis, studied with laminagraphy and standardized occlusal films. J Clin Orthod 1976; 10: 882.

5. Melsen B, Allais D. Factors of importance for the development of dehiscences during labial movement of mandibular incisors: a retrospective study of adult orthodontic patients. Am J Orthod Dentofacial Orthop 2005; 127: 552-561.

6. Boyd RL, Leggott PJ, Quinn RS, Eakle WS, Chambers D. Periodontal implications of orthodontic treatment in adults with reduced or normal periodontal tissues versus those of adolescents. Am J Orthod Dentofacial Orthop 1989; 96: 191-198.

7. Årtun J, Krogstad O. Periodontal status of mandibular incisors following excessive proclination A study in adults with surgically treated mandibular prognathism. Am J Orthod Dentofacial Orthop 1987; 91: 225-232.

8. Rupprecht RD, Horning GM, Nicoll BK, Cohen ME. Prevalence of dehiscences and fenestrations in modern American skulls. J Periodontol 2001; 72: 722-729.

9. Larato D. Alveolar plate fenestrations and dehiscences of the human skull. Oral Surg Oral Med Oral Pathol 1970; 29: 816-819.

10. Leung CC, Palomo L, Griffith R, Hans MG. Accuracy and reliability of cone-beam computed tomography for measuring alveolar bone height and detecting bony dehiscences and fenestrations. Am J Orthod Dentofacial Orthop 2010; 137: S109-119.

11. Evangelista K, De Faria Vasconcelos K, Bumann A, Hirsch E, Nitka M, Silva MAG. Dehiscence and fenestration in patients with Class I and Class II Division 1 malocclusion assessed with cone-beam computed tomography. Am J Orthod Dentofacial Orthop 2010; 138: 133-e1.

12. Wehrbein H, Bauer W, Diedrich P. Mandibular incisors, alveolar bone, and symphysis afterorthodontic treatment. A retrospective study. Am J Orthod Dentofacial Orthop 1996; 110: 239-246.

13. Sarikaya S, Haydar B, Ciǧer S, Ariyürek M. Changes in alveolar bone thickness due to retraction of anterior teeth. Am J Orthod Dentofacial Orthop 2002; 122: 15-26.
14. Lupi JE, Handelman CS, Sadowsky C. Prevalence and severity of apical root resorption and alveolar bone loss in orthodontically treated adults. Am J Orthod Dentofacial Orthop 1996; 109: 28-37.

15. Cho HJ. A three-dimensional cephalometric analysis. J Clin Orthod 2009; 43: 235-252.

16. Garlock DT, Buschang PH, Araujo EA, Behrents RG, Kim KB. Evaluation of marginal alveolar bone in the anterior mandible with pretreatment and posttreatment computed tomography in nonextraction patients. Am J Orthod Dentofacial Orthop 2016; 149: 192-201.

17. Bresin A, Kiliaridis S, Strid KG. Effect of masticatory function on the internal bone structure in the mandible of the growing rat. Eur J Oral Sci 1999; 107: 35-44.

18. Taylor D, Lee TC. Microdamage and mechanical behaviour: predicting failure and remodelling in compact bone. J Anat 2003; 203: 203-211.

19. Lang NP, Hill RW. Radiographs in periodonties. J Clin Periodontol $1977 ; 4$ : 16-28.

20. Fuhrmann R. Dreidimensionale Interpretation von alveolären Knochendehiszenzen. J Orofac Orthop 1996; 57: 62-74.

21. Davis GR, Wong FSL. X-ray microtomography of bones and teeth. Physiol Meas 1996; 17: 121.

22. Freisfeld M, Schüller H. Anwendungsmöglichkeiten der Computertomographie in der Kieferorthopädie. Prakt Kieferorthop 1992; 6: 169-182.

23. Patcas R, Müller L, Ullrich O, Peltomäki T. Accuracy of cone-beam computed tomography at different resolutions assessed on the bony covering of the mandibular anterior teeth. Am J Orthod Dentofacial Orthop 2012; 141: 41-50.

24. Fuhrmann RAW, Wehrbein H, Langen HJ, Diedrich PR. Assessment of the dentate alveolar process with high resolution computed tomography. Dentomaxillofac Radiol 1995; 24: 50-54.

25. Sun L, Zhang L, Shen G, Wang B, Fang B. Accuracy of cone-beam computed tomography in detecting alveolar bone dehiscences and fenestrations. Am J Orthod Dentofacial Orthop 2015; 147: 313-323.

Received November 19, 2018. Accepted December 27, 2018. 